\title{
Modelo animal de anemia inducida por flebotomía crónica: Relación funcional entre hierro y eritropoyesis
}

\author{
Gaona Prieto Suani², Villarraga Muñoz María del Mar², D ‘ Anna Maria C ${ }^{1}$, Giorgi Gisela \\ Garcia Betina ${ }^{1}$, Mora Bautista Ana Isabel ${ }^{2}$, Castillo Bohórquez Martha², Roque Marta $\mathrm{E}^{1}$
}

1 Biología, Bioquímica y Farmacia. Universidad Nacional del Sur. Bahía Blanca. Argentina

2 Universidad Colegio Mayor de Cundinamarca, Facultad de Ciencias de la Salud. Bogotá, Colombia

Correspondencia: mroque@uns.edu.ar

\section{RESUMEN}

En el presente estudio se analizo la respuesta eritropoyética a la anemia inducida por flebotomía crónica y los cambios en la distribución del hierro celular y sistémico del organismo. Ratones hembra de la cepa CFl ( $n=32$ ), se dividieron en dos lotes: control y experimental, siguiendo un diseño experimental pareado según su peso. La distribución del hierro en bazo e hígado durante la flebotomía crónica fue evaluada mediante estudios morfológicos y la actividad eritropoyética mediante estudios hematológicos. Las diferencias estadísticas se determinaron mediante Test Student. El nivel de significancia se fijó en $p<0,05$.

Durante la flebotomía crónica se observó una disminución significativa de hemoglobina como indicador de anemia y reticulocitosis como indicador de la restauración del eritron. El bazo de ratón adulto fue el principal tejido que aportó el hierro biodisponible al eritrón, siendo evidente la depleción esplénica del micronutriente. El estudio de la anemia inducida de forma crónica en ratones permitió desarrollar condiciones fisiopatológicas análogas a las observadas en patologías humanas. El modelo de flebotomía crónica fue útil para evaluar la eritropoyesis en la instauración de la anemia y su recuperación, correlacionándola con la distribución de un nutriente esencial como es el hierro.

Palabras clave: anemia, flebotomia crónica, eritropoyesis, estudios hematológicos

\section{Animal Model of Anemia induced of ehronic phlebotomy: Funetional relationship between iron and erythropoiesis}

\begin{abstract}
In the present work we studied the erythropoietic response to chronic phlebotomy-induced anemia and changes in cellular and systemic body iron distribution. Female mice (CFl strain, $\mathrm{n}=$ 32) were divided into control and experimental groups, following a paired experimental design.
\end{abstract}


Iron distribution in spleen and liver during chronic phlebotomy was assessed by morphological studies and erythropoietic activity by hematological studies. Statistical differences were determined by Student test. The significance level was set at $p<0.05$. During chronic phlebotomy we observed a significantly decreased of hemoglobin as an anemia indicator and reticulocytosis as an indicator of erythron restoration. Adult mouse spleen was the main tissue that contributed available iron to the erythron, being evident splenic iron depletion. The study of chronic induced anemia in mice allowed us to the development of patho physiological conditions similar to those observed in human pathologies. The model of chronic phlebotomy was useful to evaluate the erythropoiesis in the setting of anemia and its recovery, correlating with the distribution of an essential nutrient such as iron.

Key words: Anemia, chronic phlebotomy, erythropoiesis, hematological studies

Recibido: 29-05-2012 Aceptado:28-06-2012

\section{INTRODUCCIÓN}

$\mathrm{El}(\mathrm{Fe})$ es un nutriente esencial para todos los organismos vivientes por sus propiedades como catalizador biológico (1). Es un biometal indispensable como cofactor de grupos prostéticos de proteínas y enzimas que participan en el transporte y almacenamiento de oxigeno, como el hemo. Así mismo, tiene un rol fundamental en la respuesta a agentes infecciosos.

En soluciones acuosas, el hierro se encuentra en dos estados de oxidación estables, Ferroso $(\mathrm{Fe} 2+)$ y Férrico $\left(\mathrm{Fe}^{+}+\right)$ (1). La espontanea oxidación del hierro se asocia con la reducción de otras moléculas lo que conduce a la formación de radicales libres (2). Estas especies reactivas pueden causar daño oxidativo a membranas lipídicas, proteínas y ácidos nucleicos, produciendo disfunción celular (2).

Como resultado de su potencial toxicidad y su insolubilidad, el hierro debe mantenerse en la forma soluble, no tóxica. Para ello, este micronutriente esencial debe estar constantemente unido a moléculas especializadas en la absorción, transporte y depósito, responsables de los requerimientos de hierro del organismo (3).

Debido a las características únicas del metabolismo del hierro, su balance se mantiene por un especializado mecanismo integrado que opera a nivel celular y sistémico (3). De esta forma se garantiza que los requerimientos celulares sean satisfechos sin una excesiva acumulación del metal.

La relevancia de los mecanismos regulatorios, reside en que la absorción y el almacenamiento, deben estar estrictamente regulados porque la incorporación diaria es escasa y la excreción es limitada $(2,3)$. En vertebrados la homeostasis del hierro es dominada por la falta de una ruta excretoria del exceso de hierro.

Los niveles plasmáticos de hierro son regulados por su ingreso a través de la mucosa duodenal que afecta la absorción así como por su liberación desde los macrófagos del sistema retículo endotelial, reciclando hierro de eritrocitos seniles y/o dañados $(2,3)$. El hierro hemo-férrico ingresa al enterocito mediante un transportador 
apical llamado heme carrier protein 1 ( $\mathrm{HCP} 1)$ y el Fe inorgánico es separado del grupo hemo por la hemooxigenasa (HMOX) (4). La absorción de Fe no hemo o Fe libre ha sido más estudiada.

El $\mathrm{Fe}$ en estado férrico ingresa a los enterocitos mediante la proteína $\beta 3^{-}$ integrina y posteriormente es transferido a la proteína chaperona mobilferrina (1). El complejo proteico llamado paraferritina, lo reduce al estado ferroso. El Fe férrico presente en la dieta es reducido a ferroso por la citocromo duodenal $\mathrm{B}$ (DcytB), ferri-reductasa de la membrana apical del enterocito (5).

El hierro en estado ferroso ingresa al enterocito mediado por el transportador de metales divalentes 1 (DMT1, divalent metal transporter 1) (6). En el citoplasma celular, el Fe2+ puede ser oxidado al estado férrico y formar parte de los depósitos del metal a través de su unión a ferritina, principal proteína que almacena $\mathrm{Fe}$ (7). En condiciones fisiopatológicas, la hemosiderina es la forma predominante del $\mathrm{Fe}$ de depósito (8).

Dependiendo de los requerimientos eritropoyéticos, el hierro ferroso puede ser exportado a la circulación a través del exportador ferroportina (FPN) (9). En contraste con las múltiples vías de ingreso celular, el exportador FPN constituye el único mecanismo de egreso utilizado por todos los tipos celulares que exportan Fe. Ferroportina se expresa en enterocitos, en macrófagos que reciclan hierro, en hepatocitos y en células de la placenta (10). Como se ha descripto ampliamente, hepcidina, regulador negativo del ciclo del Fe, controla los niveles del biometal interactuando con FPN, su receptor especifico. La unión de Hepcidina-FPN internaliza al exportador y reduce el egreso celular de Fe (11).

Hepcidina es sintetizada en respuesta a la inflamación y al aumento de los depósitos de Fe (12). Mientras que, la disminución de Fe plasmático, reduce la síntesis de hepcidina y a su vez aumenta la síntesis de FPN aumentando su liberación (11). El sistema regulatorio sistémico hepcidina/ FPN se comunica con el sistema regulatorio formado por un "elemento que responde al $\mathrm{Fe}$ "y "proteínas regulatorias del Fe" (IRE/IRP) y de esta forma regulan el balance del Fe celular y sistémico (13).

Hepcidina regula la liberación de Fe celular mediante sofisticados mecanismos y su expresión es regulada por los mismos factores fisiológicos que regulan la homeostasis del Fe (14). El gen de hepcidina (HAMP) está estrechamente relacionado con los genes de diversas proteínas del ciclo del Fe como hemojuvelina (HJV), la proteínas de la hemocromatosis (HFE) y el receptor de transferrina 2 (RTf-2) (15, 16). Se ha descripto que la transcripción de hepcidina sería regulada por las proteínas HJV, TfR2 y HFE (14). Podemos concluir, que el conocimiento de la modulación de la expresión de hepcidina es crítica para comprender la regulación del metabolismo del Fe.

En mamíferos, el hierro presente en el organismo se distribuye unido a la proteína Transferrina (Tf), ingresando a las células hepáticas a través del receptor de transferrina 1 (RTf-1), proceso mediado por la endocitosis del complejo RTf1-Tf-Fe3+ (17). En el endosoma, el Fe es liberado de la Tf en estado férrico y reducido a $\mathrm{Fe} 2+$ mediante la reductasa endosomal STEAP3 (18). En estado ferroso es transportado hacia el citoplasma celular 
mediante DMT1, y luego de su liberación endosomal el receptor es reciclado (18). Otra segunda vía de ingreso celular es mediada por el RTf-2. El RTf-2, expresado principalmente en hepatocitos, posee un $45 \%$ de homología con el clásico RTf-1, con menor capacidad de unión a la Tf-Fe3+ y pH dependiente (17). A diferencia del RTf-1, el RTf-2 no posee IRE en su secuencia génica, de modo que los niveles locales de Fe no regulan cambios en su expresión (17).

En humanos, el eritrón requiere $20 \mathrm{mg} /$ día para el desarrollo de los precursores eritroides y células maduras. Sin embargo, sólo se incorporan 1-2 mg/día por absorción intestinal (10\% del Fe de la dieta). Por lo que, el proceso de fagocitosis de eritrocitos senescentes por los macrófagos del sistema retículo endotelial es indispensable para cubrir los requerimientos diarios del eritrón (19).

Por lo tanto, es claro que la anemia es el punto cardinal de la deficiencia de Fe, uno de los déficits nutricionales más frecuentes en el mundo $(21,21)$. Su prevalencia es mayor en niños y en mujeres en edad fértil, sobre todo entre las embarazadas. En los niños, el déficit de hierro causa retrasos en el desarrollo y trastornos del comportamiento, y en mujeres gestantes incrementa el riesgo de parto prematuro y de tener un recién nacido de bajo peso (20).

Se distinguen tres estadios progresivos de intensidad sintomática creciente en la anemia por déficit de hierro (22): 1) Ferropenia latente: de curso asintomático. Se inicia el vaciamiento de los depósitos férricos del sistema retículo endotelial, primero en hígado y bazo y, después, en médula ósea; 2) Ferropenia sin anemia: aumenta el déficit de hierro, con mayor compromiso de los datos analíticos, aunque sin afectar el hemograma, y por aparición de sintomatología atribuible al déficit de enzimas tisulares que contienen Fe, pero sin clínica de anemia; 3) Anemia ferropénica: mayor afectación de las anomalías previas y alteraciones hematológicas propias, así como sintomatología de anemia.

Diversos parámetros hematológicos presentan semejanzas y diferencias entre humanos y mamíferos pequeños (23), como se observa en la Tabla 1:

Tabla 1. Parámetros hematológicos presentan semejanzas y diferencias entre humanos y mamíferos pequeños.

\begin{tabular}{|c|c|c|}
\hline Parámetro & Humano & Ratón \\
\hline Hemoglobina & $13-17 \mathrm{~g} / \mathrm{dL}$ & $13-17 \mathrm{~g} / \mathrm{dL}$ \\
\hline Reticulocitos & $0-2 \%$ & 3 ó 4 veces mayor \\
\hline Vida media glóbulos rojos & 120 días & $44-55$ días \\
\hline $\begin{array}{c}\text { Órgano hematopoyético } \\
\text { en la adultez }\end{array}$ & Médula Ósea & Bazo \\
\hline
\end{tabular}




\section{MATERIALES Y MÉTODOS}

\section{Animales}

Se usaron 32 ratones hembra cepa $\mathrm{CF} 1$ de 2 meses de edad y $30 \pm 5 \mathrm{~g}$ de peso, provistos por el Bioterio de la Universidad Nacional del Sur. Los animales tuvieron acceso libre a agua y alimento, control diario de peso, y respetando el ciclo de luz/oscuridad de 12 hs. Se mantuvieron bajo condiciones óptimas de temperatura $\left(22 \pm 2^{\circ} \mathrm{C}\right)$ y humedad $(60 \pm 10 \%)$. El uso y cuidado de los animales fueron acordes a la "Guide of the Care and Use of Laboratory Animals" (24)

\section{Diseño experimental}

Los ratones se dividieron en dos grupos siguiendo un diseño estadístico pareado: 1) Grupo Experimental (flebotomía crónica), a los cuales se les realizó extracciones de $500 \mu \mathrm{l}$ de sangre cada 2 días durante 28 días, bajo anestesia con eter etílico; 2) grupo control, se los anestesió cada 2 días con eter etílico sin extraer sangre durante 28. Entre los días 28 y 32 no se realizaron extracciones sanguíneas. Los animales fueron sacrificados los días 10, 28 y 32.

\section{Estudios hematológicos}

Las muestras se obtuvieron por extracción sanguínea del seno retro-orbital mediante el uso de capilares heparinizados en los días de sacrificio. Para evaluar el estaedo del eritrón se realizó: Hematocrito: método de microhematocrito; Hemoglobina: método de la cianometahemoglobina (Kit colorimétrico de Wiener); Reticulocitos: Coloración supra vital con azul brillante de cresilo. Evaluación morfológica de las células sanguíneas y de las infecciones a través de la Fórmula Leucocitaria, teñida con May-Grunwald Giemsa.

\section{Evaluación del Fe}

Hierro plasmático: La ferremia se cuantificó por un método colorimétrico mediante el Kit Fer Color de Wiener.

Hierro Tisular: 1) Cuantificación de Hierro tisular : Porciones de tejido hepático y esplénico son deshidratadas a $105^{\circ} \mathrm{C}$ durante 8 horas y sometidas a digestión química con ácido nítrico 35\% a $70^{\circ} \mathrm{C}$ durante 60 minutos. Posteriormente se neutraliza y se valora el hierro total por método colorimétrico (Kit Fer Color de Wiener); 2) Tinción de Perl's: Los tejidos esplénicos y hepáticos, se fijaron en formol 10\% en buffer de ensayo durante 18 horas. Luego de la deshidratación con alcoholes de graduación creciente fueron embebidos en parafina. Se obtuvieron cortes de $5 \mathrm{um}$ de espesor que fueron coloreadas con la tinción de Perl's, para evidenciar el hierro almacenar como Hemosiderina.

\section{Análisis estadísticos}

Los resultados obtenidos se expresan como la media aritmética \pm el error estándar de la media. Las diferencias estadísticas se determinaron por T Student. El nivel de significancia se fijó en $\mathrm{p}<0,05$.

\section{RESULTADOS}

\section{Parámetros Hematológicos}

Hemoglobina y Hematocrito: El análisis de la variación de la hemoglobina, figura 1, reflejó una disminución significativa en el día 10 en el grupo experimental $(12,9 \mathrm{~g} / \mathrm{dl}$ 
$\pm 1,3)$, respecto al grupo control $(14,6 \mathrm{~g} / \mathrm{d}$ $\pm 0,3)$. Los valores de $\mathrm{Hb}$ disminuyeron progresivamente en el grupo flebotomizado, mostrando una disminución significativa el día $28(11,2 \mathrm{~g} / \mathrm{dl} \pm 1, \mathrm{O}$ vs $13,9 \mathrm{~g} / \mathrm{d}$ $\pm 0,1)$. La Hb retornó a sus niveles basales una semana después del cese del estímulo $(14,4 \mathrm{~g} / \mathrm{dl} \pm 0,3$ vs $14,3 \pm 0,4 \mathrm{~g} / \mathrm{dl})$.

El HCT mostró similar comportamiento, evidenciando además una diferencia estadísticamente significativa con respecto al control el día 28 , figura 2.

Reticulocitos: Los reticulocitos del grupo flebotomizado, figura 3 , aumentaron el día $10(12,5 \% \pm 0,8)$ y el día $28(14,5 \%$ $\pm 1,3$ ) respecto a los controles (Día 10:

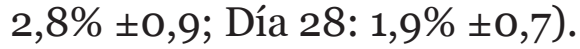

En la figura $4 \mathrm{D}$ se observa el aumento de reticulocitos (flecha) en el grupo con flebotomía durante diferentes etapas de la experimentación con respecto al grupo control.
Fórmula leucocitaria: No se observaron alteraciones en las serie leucocitaria a lo largo de la experiencia (datos no mostrados).

\section{Distribución del hierro}

Hierro plasmático: Presentó un aumento estadísticamente significativo, figura 5 , el día 28 en el grupo flebotomizado $(326,5 \mathrm{ug} / \mathrm{dL}$ $\pm 23,2)$, respecto al Grupo Control (235,1 ug/dL $\pm 26,0$ ) evidenciando los cambios de la Ferremia en flebotomía crónica.

\section{Hierro esplénico}

\section{Evaluación cualitativa del hierro esplénico}

Cuando se evaluó el contenido de Hierro en forma de hemosiderina en el grupo experimental se observó una disminución gradual de las reservas de hierro esplénico el día 28 del protocolo experimental. Una posterior recuperación fue observada tras una semana del cese del estímulo como se evidencia en la figura 6.

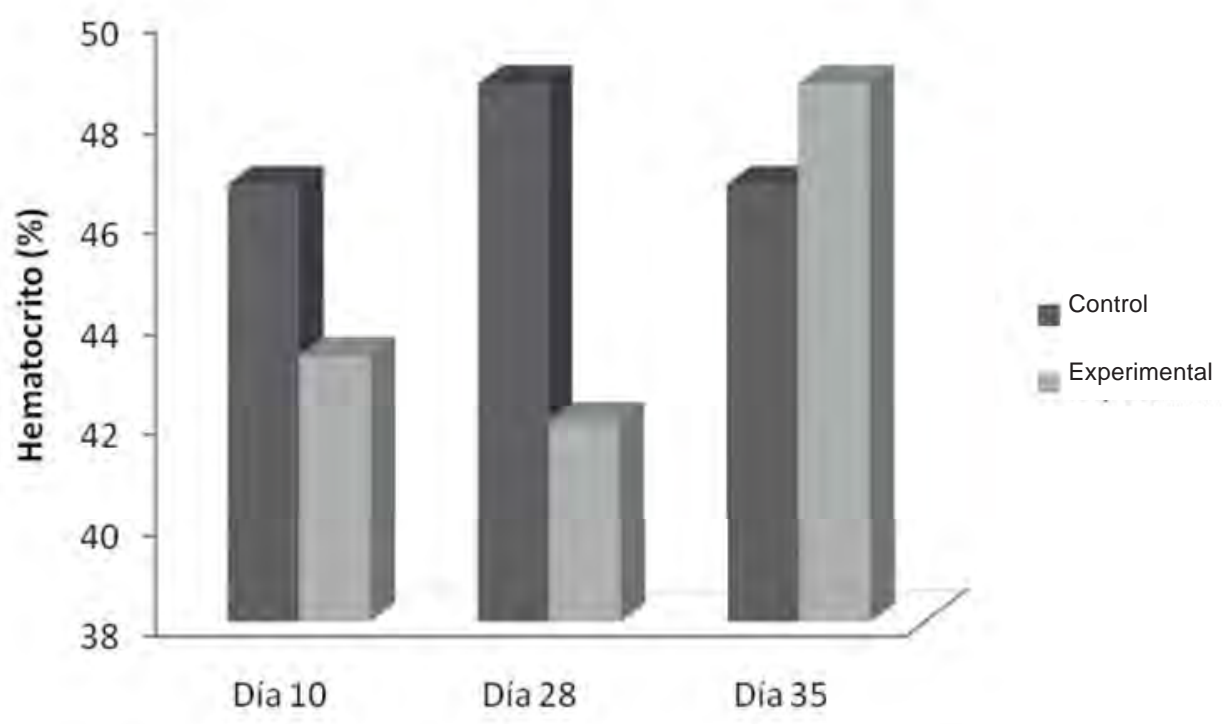

Figura 1. Variación de la hemoglobina en Flebotomía Crónica. Las muestras se procesaron como se describe en Materiales y Métodos. 


\section{Evaluación cuantitativa del hierro esplénico}

En el grupo experimental se observo una disminución del hierro estadísticamente significativa los días 10 y 28 del protocolo experimental $(14,6 \mathrm{umol} / \mathrm{gr}$ $\pm 2,8$ y $6 \mathrm{umol} / \mathrm{gr} \pm 2,3$ respectivamente), respecto a lo hallado en el grupo control $(53,9 \mathrm{umol} / \mathrm{gr} \pm 8,5 \mathrm{y} 56 \mathrm{umol} / \mathrm{gr} \pm 25,9$ respectivamente). La disminución del hierro esplénico sugiere que este tejido actuó como órgano proveedor de hierro eritropoyético, figura 7 .

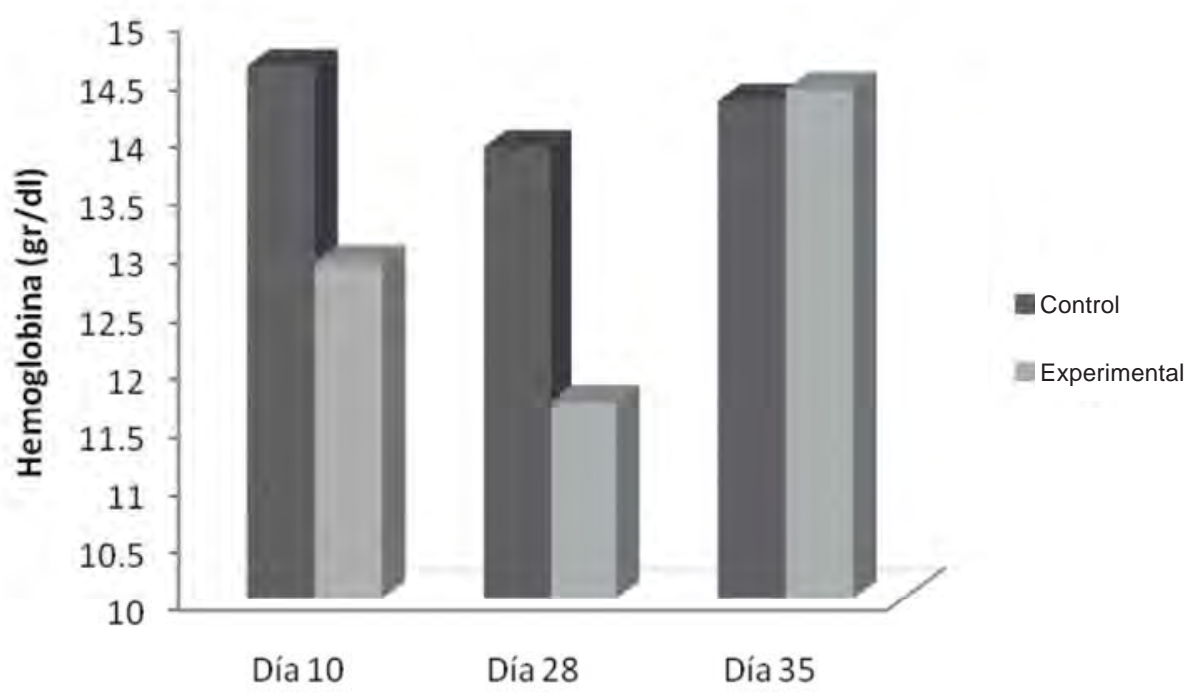

Figura 2. Variación del hematocrito en flebotomía crónica. Las muestras se procesaron como se describe en Materiales y Métodos.* $p<0,05$

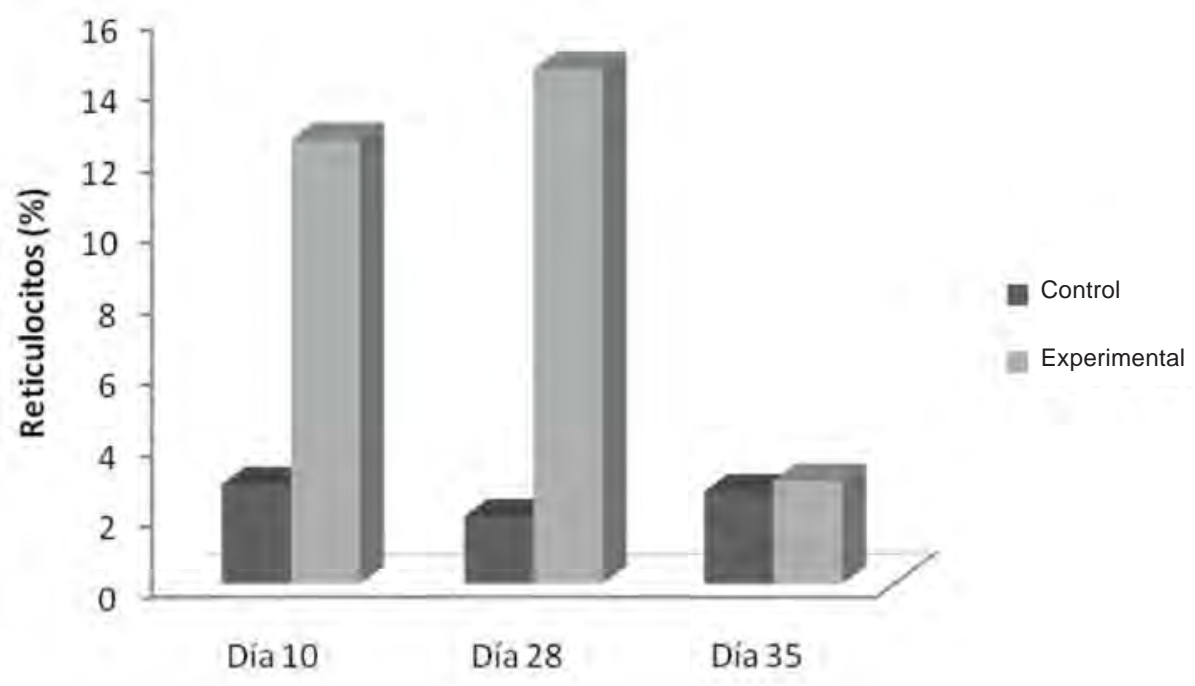

Figura 3. Respuesta reticulocitaria en flebotomía crónica. Las muestras se procesaron como se describe en Materiales y Métodos. . * $p<0,05$. 

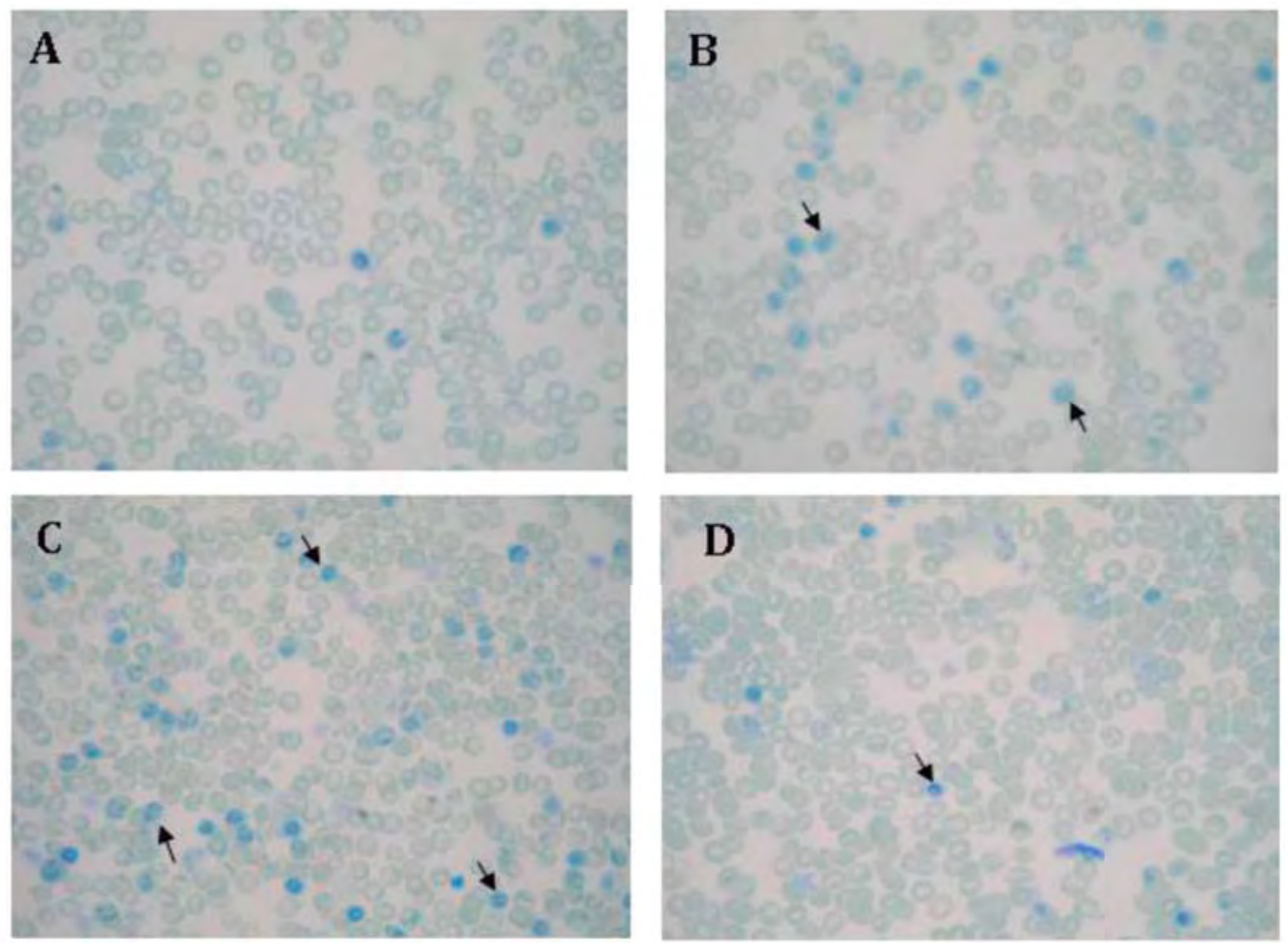

Figura 4. Imagen de reticulocitos en flebotomía crónica. Las muestras se procesaron como se describe en Materiales y Métodos.1000x A: Cantidad basal de reticulocitos en el grupo control. B: Aumento de reticulocitos (flecha) en el grupo con flebotomía día 10 de la experimentación. C: Aumento de reticulocitos (flecha) en el grupo con flebotomía día 28 de la experimentación. D: Disminución de reticulocitos (flecha) en el grupo con flebotomía una semana después de las flebotomías (semana de recuperación).

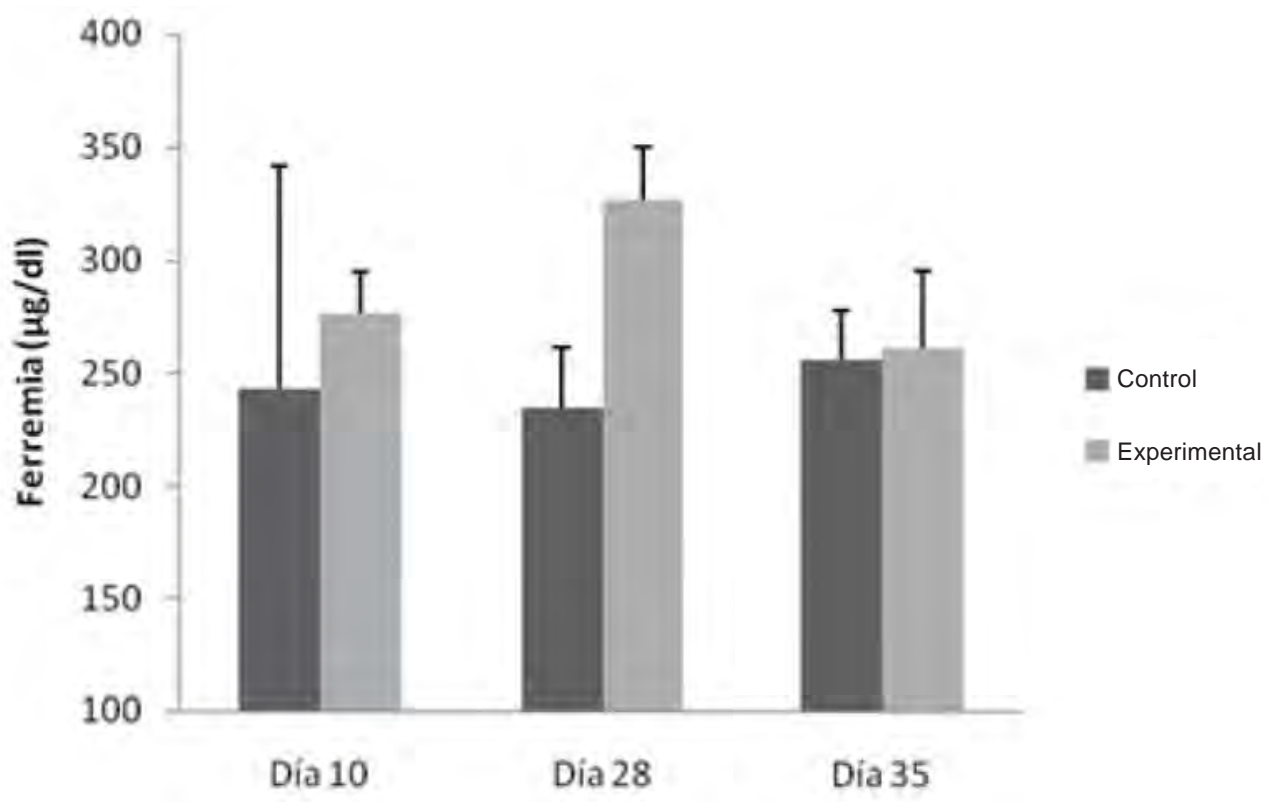

Figura 5. Variación de la Ferremia en Flebotomía Crónica.

Las muestras se procesaron como se describe en Materiales y Métodos. ${ }^{*} p<0,05$. 

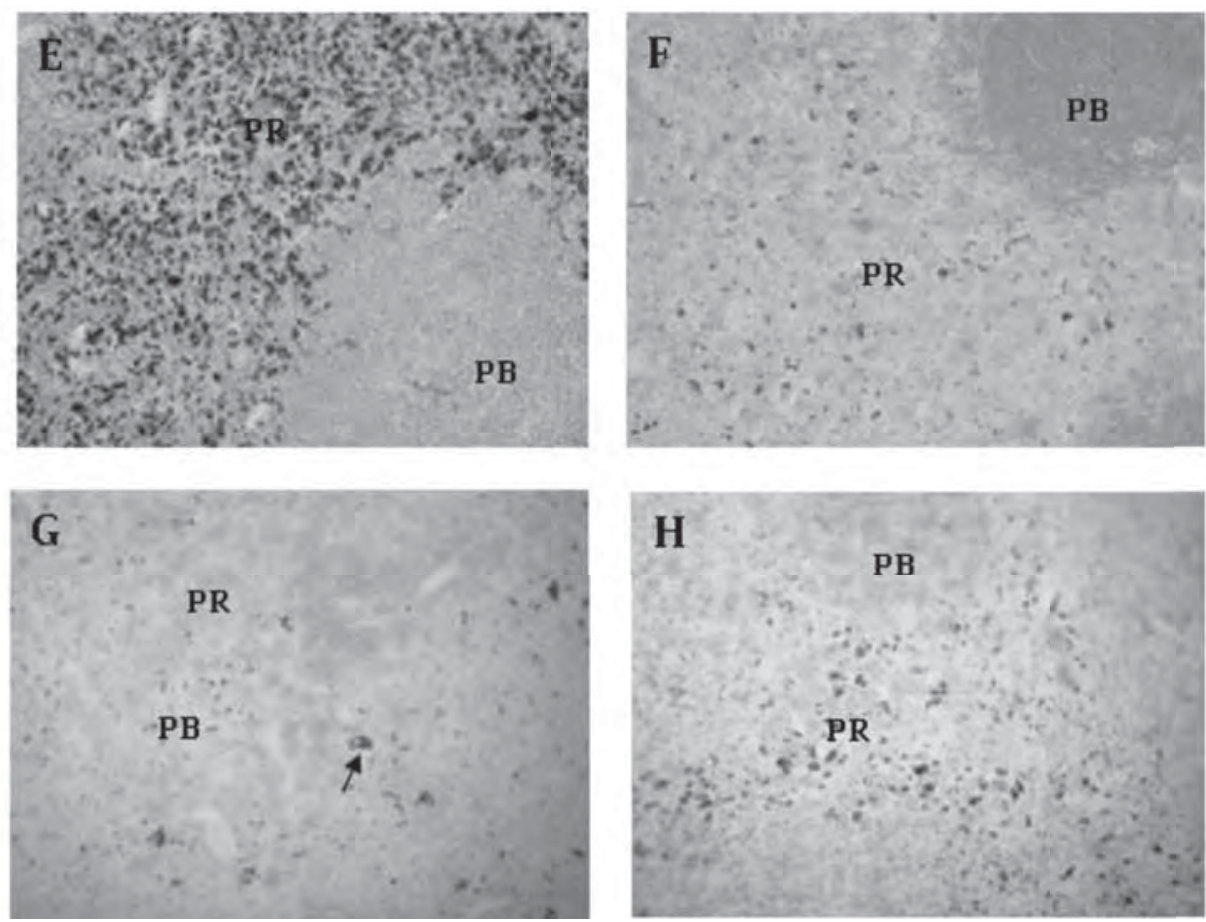

Figura 6. Evaluación cualitativa del hierro en Flebotomía Crónica.

Las muestras fueron procesadas por el método de Tinción de Perl's como se describe en Materiales y Métodos. E: Grupo Control, Fe esplénico almacenado como Hemosiderina (azul). F: Grupo Experimental, disminución del Fe esplénico (día 10 del protocolo experimental). G: Grupo Experimental, disminución del Fe esplénico día (28 del protocolo experimental). H: Grupo Experimental, restauración del Fe esplénico una semana después de la recuperación. 400x. Las muestras se procesaron como se describe en Materiales y Métodos.

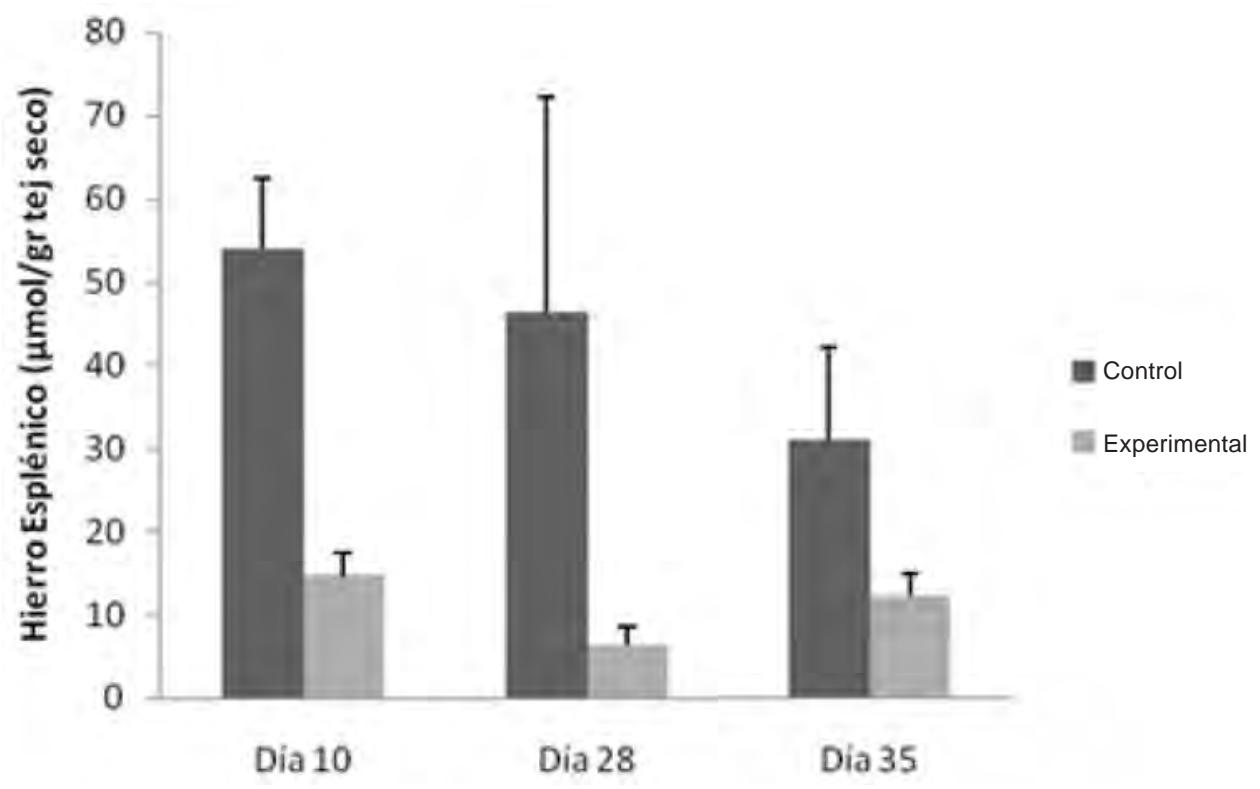

Figura 7. Evaluación del hierro esplénico en Flebotomía Crónica. Las muestras se procesaron como se describe en Materiales y Métodos. * $p<0,05$ 


\section{Hierro hepático}

Evaluación cualitativa del hierro hepático

El hierro hepático no fue visible mediante la técnica de Perls, como se observa en la figura 8.

\section{Evaluación cuantitativa del hierro hepático}

La evaluación del contenido de hierro hepático mostró una disminución estadísticamente significativa el día 28 en el grupo experimental, respecto al grupo control (1,4 umol/gr $\pm 0,3$ y $2,6 \mathrm{umol} / \mathrm{gr}$ $\pm 0,5$ respectivamente), figura 9 .

\section{DISCUSIÓN}

El animal de laboratorio es una herramienta fundamental en las ciencias biomédicas debido que son usados como modelos para comprender la etiología, diagnóstico y tratamiento de enfermedades que afectan a humanos y animales. Así mismo, el modelo animal es fundamental en la prevención y tratamiento de enfermedades transmisibles y no transmisibles (25).

El modelo de ratón de flebotomía crónica desarrollado en nuestro estudio, permitió la caracterización morfológica, bioquímica y hematológica de la eritropoyesis y de la distribución del hierro en las condiciones fisiopatológicas descritas. Específicamente, se evaluó tanto la instauración de la anemia como el proceso de restauración de la eritropoyesis y en forma paralela, los cambios en la distribución del hierro celular y sistémico en órganos con compromiso eritropoyético.

Las alteraciones hematológicas y morfológicas a nivel celular y tisular en la anemia hemolítica han sido ampliamente descriptas en la literatura. Estudios previos de nuestro grupo, describen que la instauración de anemia aguda por la droga hemótoxica fenilhidrazina (FHZ) generó alteraciones estructurales y funcionales en órganos con compromiso eritropoyético y asociados al metabolismo del hierro $(26,27)$.

Los efectos oxidativos generados por la FHZ modificaron la molécula de $\mathrm{Hb}$, con formación de cuerpos de Heinz y destrucción extravascular de los eritrocitos, dando origen al síndrome anémico.

En nuestro modelo de flebotomía crónica los cambios en los parámetros hematológicos y bioquímicos fueron característicos de aquellos descritos en flebotomía crónica (28). En el modelo animal flebotomizado, fue evidente la disminución de la $\mathrm{Hb}$, con la posterior recuperación a niveles basales. La restauración de la eritropoyesis se evidenció principalmente por la reticulocitosis manifiesta. De la observación de la fórmula leucocitaria de los ratones flebotomizados se observó que no hubo cambios en la serie leucocitaria durante el desarrollo del procedimiento experimental.

Al igual que en la anemia hemolítica, en la anemia por flebotomía, la respuesta regenerativa del eritrón tuvo gran significación en nuestro estudio. No se observaron esferocitosis y leucocitosis, fenómenos observados en la anemia hemolítica aguda $(26,27)$.

Se conoce que el bazo es el órgano encargado de retirar los eritrocitos senescentes o que presentan alguna alteración en circulación (19). En el sistema retículo endotelial esplénico el hierro queda depositado en los macrófagos. 

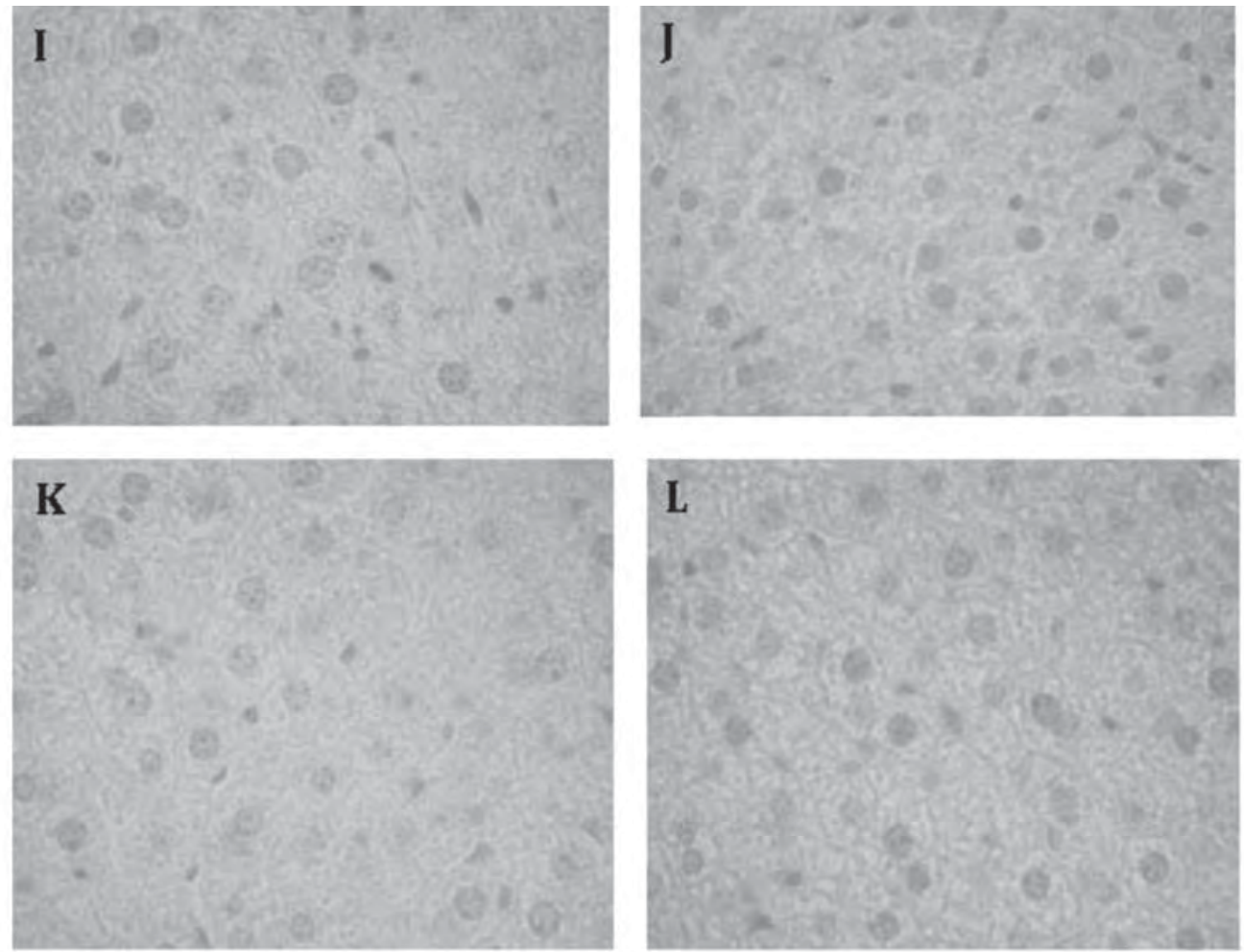

Figura 8. Evaluación cualitativa del hierro esplénico en flebotomía crónica.

Las muestras fueron procesadas por el método de Tinción de Perl's como se describe en Materiales y Métodos. I: Grupo Control no se evidencia la presencia de hierro J: Grupo Experimental en el día 10 del protocolo. K: Grupo Experimental en el día 28 del protocolo. L: Grupo Experimental después de una semana de recuperación. 1000x.

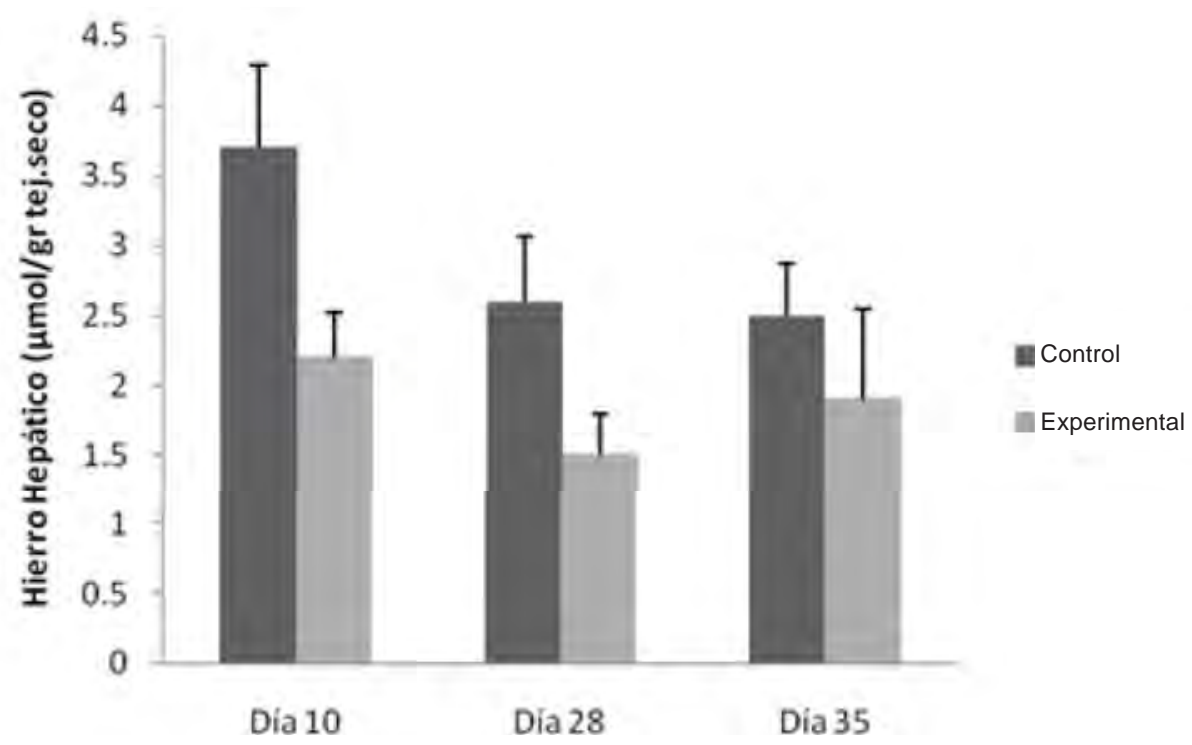

Figura 9. Hierro hepático en flebotomía crónica. Las muestras se procesaron como se describe en Materiales y Métodos. * $p<0,05$ 
En concordancia con otros autores, nuestros estudios histopatológicos claramente confirmaron la participación del bazo, en la anemia por flebotomía crónica $(26,28)$.

Nuestros estudios histopatologicos, del bazo del ratón adulto en flebotomía, evidenciaron el rol eritropoyetico del tejido esplénico. La hipertrofia del bazo, la desestructuración de la pulpa roja y la recuperación de los niveles de Hb y HCT observada en animales flebotomizados fueron indicadores de la repoblación eritropoyética.

En el modelo de anemia hemolítica aguda (AHA) se ha descripto que el efecto producido por FHZ es más agresivo que en flebotomía (29). Contrariamente a lo observado en la flebotomía, en la AHA se hace muy evidente la expansión de la línea eritrocitica por la generación de gran número de islotes eritroblásticos y de macrófagos que han fagocitado eritrocitos $(26,29)$.

De acuerdo a lo descripto en la literatura, en la anemia inducida por flebotomía ante la gran demanda de hierro para restaurar la eritropoyesis, observamos un aumento de la movilización de Fe desde los depósitos hacia los sitios principales de utilización.

En el estímulo de sangrado crónico se generó una disminución de hierro debida a la reducción de la volemia y a la activación de la eritropoyesis para compensar la anemia por flebotomía.

La ferremia en flebotomía crónica reflejó la continua movilización del Fe durante el estímulo de sangrado, para contribuir ala biodisponibilidad del Fe en la restauración de la eritropoyesis. En paralelo, el hierro esplénico del grupo flebotomizado, mostró una disminución significativa que indicó el rol del bazo como órgano proveedor de Fe eritropoyético. Este comportamiento del Fe tisular mostró al tejido hepático como un órgano proveedor de Fe en demanda intensa.

Podemos concluir que el desarrollo de anemias de distinta etiología en modelos animales es de gran importancia para realizar estudios de caracterización de eritropoyesis normal y patológica y para conocer su relación funcional con el metabolismo del hierro en situaciones de gran demanda eritropoyética.

Nuestros estudios de cuantificación de hierro tisular mostraron la participación de órganos extramedulares en la restauración la eritropoyesis, mediante el aporte de Fe necesario para compensar el estado de anemia crónica. Así mismo, se puso en evidencia la función del hígado como órgano proveedor de Fe eritropoyético en situaciones de intensa demanda. La disminución significativa del hierro esplénico en el grupo flebotomizado indica el rol principal del bazo como órgano proveedor de hierro eritropoyético cuando la eritropoyesis es muy activa.

\section{AGRADECIMIENTOS}

La investigación fue subsidiada por la Secretaría General de Ciencia y Tecnología de la Universidad Nacional del Sur. Bahía Blanca. Argentina.

\section{REFERENCIAS}

1. Pérez G, Vittori D, Pregi N, Garbossa G, Nesse A. Homeostasis del hierro. Mecanismos de absorción, captación celular y regulación. Acta Bioquím Clin Latinoam 2005; 39(3): 301-14. 
2. Dunn L, Suryo Y, Richardson D. Iron uptake and metabolism in the new millennium. Trends Cell Biol 2006; 17 (2): 93-100.

3. Ganz T. Nement E. Regulation of iron acquisition and iron distribution in mammals. Acta Biochim Biophys. 2006; 1763: 690- 9.

4. Shayeghi M, Latunde-Dada GO, Oakhill JS, Laftah AH, Takeuchi K, Halliday N, et al. Identification of an intestinal heme transporter. Cell 2005; 122: 789-801.

5. Latunde-Dada GO, Westhuizen JV, Vulpe $C D$, Anderson GJ, Simpson RJ, McKie AT. Molecular and functional roles of duodenal cytochrome B (Dcytb) in iron metabolism. Blood Cell Mol Dis 2002; 29: 356-60.

6. Mackenzie B, Garrick MD. Iron imports. II. Iron uptake at the apical membrane in the intestine. Am J Physiol Gastrointest Liver Physiol 2005; 289: 981-6.

7. Torti FM, Torti S. Regulation of ferritin genes and protein. Blood 2002; 99: 3505-16.

8. Matsuno T, Mori M, Awai M. Distribution of ferritin and hemosiderin in the liver, spleen and bone marrow of normal, phlebotomized and iron overloaded rats. Acta Med Okayama 1985; 39: 347-60.

9. D'Anna C, Veuthey $T$, Roque $M$. Immunolocalization of Ferroportin in Healthy and Anemic Mice. J Histochem Cytochem. 2009; 57(1): 9- 16.

10. Abboud S, Haile DJ. A novel mammalian iron-regulated protein involved in intracellular iron metabolism. J Biol Chem 2000; 275: 19906-12.

11. Nemeth E, Tuttle MS, Powelson J, Vaughn MB, Donovan A, Ward DM, et al. Hepcidin regulates cellular iron efflux by binding to ferroportin and inducing its internalization. Science 2004; 306: 2090-3.

12. Ganz T, Brissot P, Cohen A. Hepcidin and Its Role in Regulating Systemic I ron Metabolism. Am Soc Hematol. 2006; 1: 29- 35.

13. Muckenthaler M, Galy B, Hentze M. Systemic iron homeostasis and the Ironresponsive element/iron-regulatory protein (IRE/IRP) regulatory network. Annu Rev Nutr 2008; 28: 21-9.

14. Viatte L, Vaulont S. Hepcidin, the iron watcher. Biochimie 2009; 1-6.
15. Pantapoulos K. Function of the hemochromatosis protein HFE: lessons from animal models. World J Gastroenterol 2008; 14(45): 6893-901

16. Babitt J L, Huang FW, Xia Y, Sidis Y, Andrews NC, Lin HY. Modulation of bone morphogenetic protein signaling in vivo regulates systemic iron balance. J Clin Invest 2007; 117: 1933-9.

17. Graham RM, Chua AC, Herbison CE, Olynyk JK, Trinder D. Liver iron transport. World J Gastroenterol 2007; 13: 4725-36.

18. Tabuchi M, Yanatori I, Kawai Y, Kishi F. Retromer-mediated direct sorting is required for proper endosomal recycling of the mammalian iron transporter DMT1. J Cell Sci 2010; 123: 756-6.

19. Knutson MD, Wessling-Resnick M. Iron metabolism in the reticuloendothelial system. Crit Rev Biochem Mol 2003: 38: 61-88.

20. Shaw J, Friedman J. Iron Deficiency Anemia: Focus on Infectious Diseases in Lesser Developed Countries. Anemia. 2011; 1- 10.

21. Roque M, Gatti C, Aggio M. Estudios para evaluar el hierro corporal. Ars Pharm. 2005; 46 (2): 181- 91.

22. Arribas J, Vallina E. Hematología Clínica Temas de Patología Médica Oviedo. Textos universitarios ediuno. 2005. p 55-8.

23. Kellera G, Lacauda G, Robertsona S. Development of the hematopoietic system in the mouse. Rev Clin Exp Hematol. 1999; 27: 777- 87 .

24. Guide for the care and use of laboratory animals. National Research Council. Washington DC, 1996.

25. Fox J, Barthold S, Davisson M, Newcomer C, Quimby F, Smith F. The Mouse in Biomedical Research: Diseases. Ed. ELSEVIER. 2007; p142-50.

26. Roque M, D'Anna C, Gatti C, Veuthey T. Hematological and Morphological Analysis of the Erythropoietic Regenerative Response in Phenylhydrazine-induced Hemolytic Anemia in Mice. Scand. J. Lab. Anim. Sci. 2008; 35 (3): 181- 90 .

27. D’Anna C, Gatti C, Veuthey T, Sánchez M, Roque M. Eritropoyesis y Esplenectomía en un Modelo Murino. Rev Cientf AMBB. 2006; 16 (4): $88-9$ 
28. Camberlein $\mathrm{E}$, Abgueguen $\mathrm{E}$, Fatih $\mathrm{N}$, François Hergaux C, Leroyer P, Turlin B, et al. Hepcidin induction limits mobilisation of splenic iron in a mouse model of secondary iron overload. Elsevier.2002; 339- 46.
29. Latunde-dada GO, AT McKie \& RJ Simpson: Animal models with enhanced erythropoiesis and iron absorption. Biochim Biophys Acta 2006, 1762, 414-423. 